\title{
The role of private general practitioners in the treatment of alcohol dependence in the Free State province
}

\author{
Van Zyl PM, MBChB, MMedSc, PhD, Senior Clinical Pharmacologist/Senior Lecture \\ Department of Pharmacology, Faculty of Health Sciences, University of the Free State, Bloemfontein \\ Gagiano CA, MBChB, MMed, MD, Emeritus Professor, Department of Psychiatry, Faculty of Health Sciences, University of the Free State \\ Mollentze WF, MD, FCP(SA), MMed(Int), FACE, FRCP, Head, Department of Internal Medicine, \\ Faculty of Health Sciences, University of the Free State, Bloemfontein \\ Snyman JS, MBChB, MPharmMed, MD, Head, Department of Pharmacology, University of Pretoria; Agility Global Health Solutions, Johannesburg \\ G Joubert, BA, MSc, Head, Department of Biostatistics, Faculty of Health Sciences, University of the Free State, Bloemfontein \\ Correspondence to: Paulina van Zyl, e-mail address: vzylpm@ufs.ac.za \\ Keywords: private general practitioners, treatment, alcohol, dependence, Free State province, South Africa
}

\section{Abstract}

Objectives: The study was undertaken to investigate the role of private general practitioners (GPs) in the treatment of alcohol dependence in the Free State province.

Design: A descriptive cross-sectional study. A questionnaire was used to describe the experiences of GPs with patients with alcohol dependence.

Outcome measures: The treatment role of individual participants was defined in terms of the range of services provided and the enablers and obstacles faced in performing interventions in their local context.

Setting and subjects: Seventy-seven private GPs were selected by means of a stratified randomised sampling process from areas in the immediate proximity of regional hospitals, district hospitals, or basic environments (without local hospital services), in three geographical areas defined by existing health service delivery boundaries.

Results: $29.9 \%$ of participants practised medical detoxification, either in hospital or in outpatient settings. Involvement related to the local organisation of treatment services in a geographical area. GPs in resource-constrained environments played an extended role outside of the traditional office-based model of care. Medical scheme funding policies were regarded as an obstacle to involvement in the treatment of alcohol-dependent patients by $76.5 \%$ of participants. Other major obstacles were lack of multidisciplinary teams, in-patient facilities and referral structures.

Conclusion: Private GPs in the Free State play a context-dependent role in the treatment of alcohol-dependent patients in the province. This compensatory role needs to be acknowledged in service delivery planning in under-resourced areas, especially to ensure access to treatment and cost-effective management.

\section{Introduction}

The Prevention of and Treatment for Substance Abuse Act of $2008^{1}$ requires service providers involved in the treatment of substance-dependent persons to register and comply with minimum standards, namely appropriate training and proving their ability to provide follow-up care. The Minister of Social Development takes responsibility for the development of a strategy that includes medical treatment, and also to contract or provide funding to service providers. The Act expands the role of treatment centres to provide obligatory outpatient and reintegration services, and to make provision for community-based intervention, ${ }^{1}$ which may have implications with regard to the role of medical practitioners.
Data collected by the South African Community Epidemiology Network on Drug Use (SACENDU) project identified private general practitioners (GPs) as an important source of referrals to treatment centres. ${ }^{2}$ According to SACENDU data, alcohol dependence is still by far the most common reason for admission to treatment centres in the Free State. However, treatment provided by GPs and the full extent of their involvement has not been described by this project.

The aim of our study was to investigate the role of various groups of healthcare professionals in the treatment of several categories of substances. In this article, we report on the role that private GPs currently play in the treatment of alcohol dependence in the Free State province. 


\section{Method}

Ethical approval was granted by the Ethics Committee of the Faculty of Health Sciences, University of the Free State (ETOVS No: 38/06).

A descriptive cross-sectional study was performed during the two-year period 2007-2008. A database of medical professionals was compiled from the 2005 Telkom telephone directory listing private GPs. The database was stratified according to the existing geographical boundaries of the three health service delivery units of the Free State Department of Health. A random selection of geographical areas was carried out, followed by a random selection of participants in each area using randomisation tables. ${ }^{3}$ One hundred and twenty-three GPs were selected in this manner, and contacted telephonically to set up an appointment. Thirty of these were not practising anymore because of emigration, retirement or death. Fourteen declined, of whom nine indicated that they were not involved with the treatment of alcohol dependence. Two were excluded after repeatedly failing to keep appointments. Thus, 77 private GPs participated in the study.

A questionnaire was compiled by the team of researchers, supported by the Department of Biostatistics. Questions were formulated to reflect the role that participants played in the treatment of substance dependence, factors that supported them and obstacles. A pilot study was performed with three GPs who were excluded from the pool.

One researcher (PMvZ) completed the questionnaires during face-to-face appointments. Respondents were guaranteed anonymity to prevent them from withholding information, and told that they could not gain anything from providing false information. They were also not influenced to provide so-called "correct" answers, or briefed on expected outcomes. In order to promote a positive attitude by the respondents towards the research process, care was taken to respect their time schedules by advance booking, and allowing sufficient time between interviews.

In this article, we report on the quantitative aspects that relate to the role of GPs in the treatment of alcohol dependence.

\section{Definition of terms}

Participants were asked about their interaction with patients who presented to them seeking help for alcohol dependence. The interpretation of the term "alcohol dependence" was left to the participants as their actions would be determined by their individual perception of the problem at hand. Therefore in this study, alcohol dependence referred to a situation in which, in the doctor's opinion, a person's use of alcohol was of such a nature that it required medical intervention.

Data were presented as a horizontal view of the situation in three geographical contexts in the Free State province, each representing a different combination of state and public healthcare services. The Southern Health Complex has the highest concentration of private psychiatrists and private hospitals, as well as a recognisable referral system for the treatment of alcohol dependence in the public sector. The Northern Health Complex has limited access to one private psychiatrist, one private facility per regional environment, and limited provision for the medical treatment of alcohol dependence in the public sector. The Eastern Health Complex has one psychiatrist who provides services to the public and private sectors, one private hospital, and one state hospital that offers medical withdrawal from alcohol in cases other than unplanned withdrawals which occur while patients are hospitalised for unrelated conditions.

The data are further presented in a vertical split into three levels of service environment, representing levels of service ranging from urban to increasingly rural. Regional environments were those areas within a $20-\mathrm{km}$ radius of a regional state hospital. District environments were within $20 \mathrm{~km}$ of a district hospital, and basic environments had no local hospital. Results are reported as percentages.

\section{Results}

\section{Response rate}

Fourteen of the 93 eligible selected participants declined the telephonic invitation to participate in the study. A further two participants were excluded because of repeatedly failing to attend appointments.

\section{The age and experience of the private general practitioners}

Seventy-seven private GPs participated in the study. As shown in Table I, the median age and years since qualification of private GPs in the Northern Health Complex were considerably higher than those of participants in the

Table I: Participating general practitioners' median age and years after qualification per geographical area and level of healthcare service

\begin{tabular}{|l|c|c|}
\hline Characteristics & $\begin{array}{c}\text { Median age in } \\
\text { years (range) }\end{array}$ & $\begin{array}{r}\text { Median years } \\
\text { after qualification } \\
\text { (range) }\end{array}$ \\
\hline \begin{tabular}{l} 
Geographical area \\
\hline $\begin{array}{l}\text { Northern Health Complex } \\
(n=32)\end{array}$
\end{tabular} & $54(30-85)$ & $28(7-60)$ \\
\hline $\begin{array}{l}\text { Eastern Health Complex } \\
(n=25)\end{array}$ & $42(29-73)$ & $17(6-48)$ \\
\hline $\begin{array}{l}\text { Southern Health Complex } \\
(n=20)\end{array}$ & $40(31-55)$ & $16(6-31)$ \\
\hline Service level & $45(29-74)$ & $20(6-47)$ \\
\hline Regional $(n=47)$ & $44(29-65)$ & $21(6-37)$ \\
\hline District $(n=17)$ & $43(30-85)$ & $19(7-60)$ \\
\hline Basic $(n=13)$ &
\end{tabular}


Table II: Consultations for alcohol dependence

\begin{tabular}{|c|c|c|c|c|c|c|}
\hline \multirow{3}{*}{ Characteristics } & \multicolumn{6}{|c|}{ Frequency } \\
\hline & \multicolumn{2}{|c|}{ Never } & \multicolumn{2}{|c|}{ Less than once per month } & \multicolumn{2}{|c|}{ Monthly or more } \\
\hline & $\mathbf{n}$ & $\%$ & $\mathrm{n}$ & $\%$ & $\mathrm{n}$ & $\%$ \\
\hline \multicolumn{7}{|l|}{ Geographical area } \\
\hline Northern Health Complex $(n=32)$ & 0 & 0 & 17 & 53.1 & 15 & 46.9 \\
\hline Eastern Health Complex $(n=25)$ & 2 & 8 & 16 & 64 & 7 & 28 \\
\hline Southern Health Complex $(n=20)$ & 1 & 5 & 10 & 50 & 9 & 45 \\
\hline \multicolumn{7}{|l|}{ Service level } \\
\hline Regional $(n=47)$ & 3 & 6.4 & 26 & 55.3 & 18 & 38.3 \\
\hline District $(n=17)$ & 0 & 0 & 10 & 58.8 & 7 & 41.2 \\
\hline Basic $(n=13)$ & 0 & 0 & 7 & 53.9 & 6 & 46.2 \\
\hline Total consultations $(n=77)$ & 3 & 3.9 & 43 & 55.8 & 31 & 40.4 \\
\hline
\end{tabular}

Table III: General practitioners' treatment of alcohol dependence

\begin{tabular}{|c|c|c|c|c|c|c|c|c|}
\hline \multirow[t]{3}{*}{ Characteristics } & \multicolumn{8}{|c|}{ Type of involvement } \\
\hline & \multicolumn{2}{|c|}{ None } & \multicolumn{2}{|c|}{ Refer all } & \multicolumn{2}{|c|}{$\begin{array}{l}\text { Detoxification } \\
\text { by GP }\end{array}$} & \multicolumn{2}{|c|}{$\begin{array}{l}\text { Medical follow-up } \\
\text { only }\end{array}$} \\
\hline & $\mathbf{n}$ & $\%$ & $\mathbf{n}$ & $\%$ & n & $\%$ & $\mathbf{n}$ & $\%$ \\
\hline \multicolumn{9}{|l|}{ Geographical area } \\
\hline Northern Health Complex $(n=32)$ & 2 & 6.3 & 11 & 34.4 & 14 & 43.8 & 5 & 15.6 \\
\hline Eastern Health Complex $(n=25)$ & 5 & 20 & 13 & 52 & 5 & 20 & 2 & 8 \\
\hline Southern Health Complex $(n=20)$ & 1 & 5 & 12 & 60 & 4 & 20 & 3 & 15 \\
\hline \multicolumn{9}{|l|}{ Service level } \\
\hline Regional $(n=47)$ & 6 & 12.8 & 21 & 44.7 & 17 & 36.2 & 3 & 6.4 \\
\hline District $(n=17)$ & 1 & 5.9 & 10 & 58.9 & 2 & 11.8 & 4 & 23.5 \\
\hline Basic $(n=13)$ & 1 & 7.7 & 5 & 38.5 & 4 & 30.8 & 3 & 23.1 \\
\hline Total $(n=77)$ & 8 & 7.8 & 36 & 46.8 & 23 & 29.9 & 10 & 12.9 \\
\hline
\end{tabular}

GP: general practitioner

other areas, while the Southern Health Complex had the youngest population. The median age and years since qualification were similar across the three levels of service.

\section{Exposure and involvement in the treatment of alcohol dependence}

While $40.4 \%$ of the sample of private GPs dealt with alcohol dependence on a monthly basis (Table II), 3.9\% never saw persons with alcohol dependence. Participants from the Northern and Southern Health Complexes had higher frequency of contact with help-seeking, alcohol-dependent patients than those in the Eastern Health Complex. Only marginal differences occurred between basic, district and regional environments with regard to consulting patients who sought help.

\section{Treatment roles}

The different treatment roles of private GPs with regard to alcohol dependence are shown in Table III. Participants in the Northern Health Complex were more likely to become involved in the detoxification of persons addicted to alcohol, while participants in the Southern Health Complex, with its proximity to treatment facilities, would mostly refer the patient (Table III). Compared to other regions, a higher percentage of participants in the Eastern Health Complex were not involved in the management of these cases. Table III further shows that while regional participants had the highest level of participation in medical detoxification $(36.2 \%)$, this was closely matched by the involvement of participants from basic healthcare environments (30.8\%). Because of the lack of hospitals in basic environments, these doctors could only deliver these services from their consulting rooms. A total of 15 participants (19.5\%) indicated that they would sometimes perform detoxification on an outpatient basis for selected patients.

\section{Range of services}

Table IV shows that participants in the Northern Health Complex were more likely to become involved in the medical treatment of alcohol-dependent patients. They took on an extended role that may be outside the usual office-based primary care consultation model. They had a higher degree of involvement in supporting the patient's family than other regions. The findings, summarised in Table IV, show that involvement in medical detoxification 
Table IV: The range of services delivered by general practitioners to alcohol-dependent patients per geographical area

\begin{tabular}{|l|c|c|c|c|}
\hline \multirow{2}{*}{ Type of service provided } & \multicolumn{4}{|c|}{ Geographical area } \\
\cline { 2 - 5 } & $\begin{array}{c}\text { Northern Health Centre } \\
(\mathbf{n = 3 2})\end{array}$ & $\begin{array}{c}\text { Eastern Health Centre } \\
(\mathbf{n = 2 5 )}\end{array}$ & $\begin{array}{c}\text { Southern Health } \\
\text { Centre }(\mathbf{n = 2 0 )}\end{array}$ & $\begin{array}{c}\text { Total } \\
(\mathbf{n = 7 7})\end{array}$ \\
\hline Medical relapse prevention & $22(68.8 \%)$ & $8(32 \%)$ & $5(25 \%)$ & $35(45.5 \%)$ \\
\hline Medical detoxification & $16(50 \%)$ & $8(32 \%)$ & $4(20 \%)$ & $28(36.4 \%)$ \\
\hline Support to family & $7(21.9 \%)$ & $3(12 \%)$ & $3(15 \%)$ & $13(16.9 \%)$ \\
\hline Educational programmes & $5(15.6 \%)$ & $2(8 \%)$ & $0(0 \%)$ & $7(9.1 \%)$ \\
\hline Psychiatric support & $5(15.6 \%)$ & $0(0 \%)$ & $0(0 \%)$ & $5(6.5 \%)$ \\
\hline Psychological support & $5(15.6 \%)$ & $0(0 \%)$ & $0(0 \%)$ & $5(6.5 \%)$ \\
\hline Religious support & $3(9.4 \%)$ & $0(0 \%)$ & $1(5 \%)$ & $4(5.2 \%)$ \\
\hline Group therapy & $4(12.5 \%)$ & $0(0 \%)$ & $0(0 \%)$ & $4(5.2 \%)$ \\
\hline
\end{tabular}

tended to increase with the level of available services. With regard to the level of service environment, $4(30.8 \%)$ of the private GPs from basic healthcare environments practised medical detoxification, compared to $19(40.4 \%)$ of those from regional environments and $6(35.4 \%)$ from district environments.

\section{Training}

The majority of participants had some degree of academic training in managing alcohol dependence. Nearly two thirds of private GPs had undergraduate training in the management of alcohol dependence. However, $66.2 \%$ had no in-service training and $10.4 \%$ relied exclusively on unstructured training.

Twenty-five per cent of the participants from the Northern Health Complex reported no training, compared to $12 \%$ and $15 \%$ in the Eastern and Southern complexes, respectively, which can probably be linked to the higher median age of the Northern group. They were also more likely to report unstructured in-service training (21.9\%), compared to $3.1 \%$ and $0 \%$ of GPs in the other complexes.

In addition to having received training with regard to the management of alcohol dependence, the older Northern Health Complex GPs also relied less on academic training only (31.3\%), and more on self-training in private practice (21.9\%). Of the younger population in the Southern Health Complex, 60\% received academic training only, and $25 \%$ reported a combination of academic and in-service training. Despite these differences in training, many of the less "academically" trained Northern Health Complex participants were involved in detoxification by necessity (Table IV), given the limited specialist presence in that area.

Regional participants had the highest level of training $(70.2 \%$ at undergraduate and $21.3 \%$ at postgraduate level), while district level participants showed the highest proportion of no training $(29.4 \%)$. Participants in basic healthcare environments were on par with those in regional environments with regard to undergraduate training $(69.2 \%)$, yet relied more on in-service training. $61.5 \%$ had formal in-service training and $30.8 \%$ had unstructured inservice training. None of the participants from the basic environments reported having "no training".

\section{Obstacles to involvement}

More than $50 \%$ of the GPs indicated the following as obstacles to their involvement in the treatment of alcohol dependence: medical scheme policies $(76.6 \%)$, lack of multidisciplinary support (75.3\%), lack of inpatient facilities (68.8\%), lack of visible referral structures $(67.5 \%)$ and lack of knowledge (51.9\%).

\section{Self-reported confidence}

GPs' self-reported confidence with regard to managing mild cases of alcohol dependence was highest in the Southern Health Complex (95\%), compared to $84.4 \%$ and $80 \%$ in the Northern and Eastern Health Complexes, respectively. On the other hand, GPs in basic environments reported a higher level of confidence in such cases; $92.3 \%$ compared to $83 \%$ and $88.2 \%$ in the regional and environments, respectively.

\section{Discussion}

Private GPs in the local situation provide wide geographical coverage, offer a cost advantage over psychiatrists, have knowledge of families and can provide continuity of service. Most of all, help-seeking patients with alcohol dependency often report to GPs (Table II) and receive help from them (Table III).

GPs are also well positioned to provide a personalised service that promotes the long-term therapeutic relationship needed for continued support in alcohol-dependent patients, as their ability to foster such relationships is a key function in their professional duties. However, maintaining a long-term relationship with an alcohol-dependent patient is particularly challenging, and as pointed out by Bleich et al, ${ }^{4}$ undermined by vigorous screening practices aimed at early detection of alcohol dependence. 


\section{The roles that general practitioners play}

In the local situation, the therapeutic involvement of private GPs in alcohol dependence ranged from no involvement to providing medical care through detoxification and relapse prevention (Table III). A striking feature of the role played by private GPs in this study in the treatment of alcohol dependence in the Free State was the range of services that they provided, and how these had been adapted in different environments (Table IV).

Weaver et $\mathrm{al}^{5}$ described the roles played by the primary healthcare physician in substance-dependence treatment as detection, brief intervention and the maintenance of a therapeutic relationship.

Although the local private GPs provided a wider range of services than these ideals proposed by Weaver et al, ${ }^{5}$ most of those who were actively involved in the treatment of these patients fulfilled an administrative function (Table III). The deprivation of other services seemed to be a major factor that forced them out of this primary zone of involvement (Tables III and IV), compelling the need for selfdevelopment to attain the necessary skills, as illustrated by the participants from the Northern Health Complex, where limited specialist support seemed to boost the involvement of private GPs (Tables III and IV).

Limited aims, such as vigilance and early detection, are impractical for GPs in an environment such as the Free State where a very limited number of specialist psychiatrists and treatment centres are spread unevenly across the province. In itself, centralising treatment options creates an obstacle to access to treatment. Patients may not gain access to treatment other than that provided by a private GP.

\section{General practitioners as an entry into treatment}

Local GPs preferred to react to patients requesting treatment or being reported to them, rather than performing regular screening. Should they be encouraged to screen more vigorously?

The frequently cited review by Bien et $\mathrm{al}^{5}$ highlighted the effectiveness of brief intervention in initiating change in problem drinking and promoting entry into treatment for alcohol-dependent persons. Brief intervention often follows questionnaire-based or laboratory screening, and consists of feedback on drinking status, information regarding health risks and advice on how to reduce drinking, conveyed in a supportive manner. ${ }^{6}$ In response, the World Health Organization introduced the Alcohol Use Disorders Identification Test screening questionnaire combined with brief intervention for use in primary healthcare settings. ${ }^{7}$

Bleich et $\mathrm{al}^{4}$ described the experience of private GPs who performed screening and brief intervention. These doctors reported general skepticism about the outcome of interventions, and found it difficult to integrate the system into their practice routine. Bleich et $\mathrm{al}^{7}$ concluded that vigorous screening practices aimed at the early detection of alcohol dependence might undermine patient-doctor relationships.

Rumpf et $\mathrm{al}^{8}$ found that physicians' ability to detect problem drinkers was underestimated, and that screening tools merely reminded doctors to intervene. The finding that within a population of high alcohol consumption, ${ }^{9}$ several private GPs reporting that they had never encountered patients seeking help for this condition, could probably relate to the fact that a particular quality of patient-doctor relationship must exist for the self-report of alcohol dependence to occur. Likewise, effective follow-up care would be directly dependent on a long-term relationship between the patient and the doctor.

\section{General practitioners performing detoxification}

The current trend in the treatment of alcohol dependence is to move towards intervention at a less specialised level. ${ }^{10-12}$ This shift has particularly been facilitated by the demonstration of greater cost-efficiency of outpatient versus inpatient detoxification programmes for mild to moderate cases of alcohol withdrawal. ${ }^{11}$

In our study, private GPs expressed a relatively high level of confidence in their ability to manage outpatient withdrawal in mild alcohol withdrawal cases, yet few engaged in outpatient withdrawals. Except for the Northern Health Complex, the standard modus operandi of GPs tended to be the referral of alcohol-dependent patients to specialised treatment centres or psychiatrists. Office-based withdrawals were only performed by a few participants, and then only when economic pressures dictated such intervention.

Our findings suggest that the participation of GPs diminished where easier access to specialised facilities was available. More GPs become involved when a lack of alternatives existed in an environment, yet with access to the opinions of specialist consultants. Therefore, the GPs were flexible and able to adapt to local conditions, provided that some level of specialist support existed.

\section{Funding}

The regulations of Section 29(1) of the Medical Schemes Act No 131 of 1998 define the prescribed minimum benefit (PMB) package, a core benefit package that medical schemes are obliged to cover. ${ }^{13}$ Limitations in terms of time allocation for withdrawal (three days) and frequency of treatment (three weeks per year for rehabilitation) are inadequate in some cases. The PMB and its limitations may thus contribute to the entrenchment of addiction medicine at a specialist level as relapses are inherent in alcohol dependence. Participants reported that in general, medical schemes did not pay for admission or treatment for alcoholrelated problems. 
Many cases of alcohol withdrawal do not require hospital admission. ${ }^{10-12}$ On the other hand, withdrawal on an outpatient basis could be potentially risky, and presents a challenge to the attending doctor, demanding personal 24-hour availability, or the availability of a proper substitute, and daily follow-up during the withdrawal period. ${ }^{10}$ It also requires the patient to be trustworthy and committed, with a supportive home environment. These conditions may be difficult to establish in those cases where detoxification is needed the most. However, primary care physicians could play a significant treatment role if they employed a screening process involving risk assessment with appropriate withdrawal symptom scales, such as that suggested by the National Institute for Health Care and Excellence clinical guideline number $100 .{ }^{12}$ Subsequent risk categorisation then determines the need for hospitalisation or specialist referral. As an overall strategy, this may serve to reduce the cost of treatment dramatically for involved stakeholders, and simultaneously allow access to treatment and effective intervention in cases previously deterred by high costs. It may be possible that the involvement of GPs may be enhanced by contact sessions with evidence-based researchers in primary care on what works and what is appropriate.

\section{Limitations of the study}

The small number of participants prevented statistically significant comparisons from being made between the demarcated areas. The study was based on recall, and could therefore provide only broad estimates of the number of patients who consulted and were treated. The study did not investigate the relative weight of out-of-pocket paying patients to medical scheme-funded patients in each practice, which could have affected the generalisability of the conclusions.

\section{Future prospects}

The implementation of the new The Prevention of and Treatment for Substance Abuse Act of $2008^{1}$ means that service providers will have to register and show evidence of training. This is an opportunity for GPs to take on an expanded role in alcohol dependence management in primary care. The introduction of National Health Insurance is a potentially critical cusp for the treatment of alcohol dependence in the long term. Future research should record the influence of the implementation of these policy initiatives on the treatment of alcohol dependence.

\section{Conclusion}

Private GPs, especially in areas with rudimentary treatment infrastructure, hold an important key to the accessibility of treatment services. In support of cost-effective intervention and wide geographical coverage, the role played by private GPs in the treatment of alcohol dependence should be acknowledged. The new Act may be a vehicle with which to create incentives to maintain their involvement, and to develop their role to the benefit of a comprehensive service delivery model. Such a model should also aim to create a conducive and supportive environment, with proper treatment protocols and referral routes into private and public facilities. Agreements to ensure logistical support, in terms of hospital back-up and transport, and openness in negotiations on funding by the medical schemes, will be crucial in making such a system operational.

\section{Acknowledgements}

Acknowledgement is given to institutions that opened their doors and the individual participants who shared their thoughts, and Dr Daleen Struwig, medical writer, Faculty of Health Sciences, University of the Free State, for the technical and editorial preparation of the manuscript.

\section{Declaration}

Funding was provided by the Hendrik Vrouwes Trust and the Faculty of Health Sciences, University of the Free State.

\section{Conflict of interest}

The authors declare no conflict of interest. No contractual constraints on the publishing of the findings were imposed by the funding bodies.

\section{References}

1. Department of Social Development, Republic of South Africa. Prevention of and treatment for Substance Abuse Act (Act No 70 of 2008). Government Gazette. 2009;526(32150):1-37 [homepage on the Internet]. c2011. Available from: http:// www.info.gov.za/view/DownloadFileAction?id=99550

2. Plüddemann A, Dada S, Parry C, et al. Monitoring alcohol and drug abuse trends in South Africa (July 1996-June 2008). 2008. c2012. Available from: http://www. sahealthinfo.org/admodule/sacendu/sacendudec2008.pdf

3. Van Zyl PM, Gagiano CA, Mollentze WF, et al. Help-seeking by substance dependents presenting to health care professionals in the Free State Province. S Afr J Psychiatry. 2012;18:96-102.

4. Beich A, Gannik D, Malterud K. Screening and brief intervention for excessive alcohol use: qualitative interview study of the experiences of GPs. BMJ. 2002;325(7369):870-874

5. Weaver MF, Jarvis MA, Schnoll SH. Role of the primary care physician in problems of substance abuse. Arch Intern Med 1999;159(9):913-924.

6. Bien TH, Miller WR, Tonigan JS. Brief interventions for alcohol problems: a review. Addiction. 1993;88(3):315-335.

7. Babor TF, Higgins-Biddle JC. Brief intervention for hazardous and harmful drinking: a Manual for use in primary care. WHO [homepage on the Internet]. 2001. c2012. Available from: http://whqlibdoc.who.int/hq/2001/who_msd_msb_01.6b.pdf

8. Rumpf HJ, Bohlman J, Hill A, et al. Physicians' low detection rates of alcohol dependence or abuse: a matter of methodological shortcomings? Gen Hosp Psychiatry. 2001;23(3):133-137.

9. Department of Health, Medical Research Council, OrcMacro. South African Demographic and Health Survey 2003. Pretoria: Department of Health [homepage on the Internet]. 2007. c2011. Available from: www.doh.gov.za/www.mrc.ac.za/ bod/bod.htm

10. Asplund CA, Aaronson JW, Aaronson HE. 3 regimens for alcohol withdrawal and detoxification. J Fam Pract. 2004;53(7):545-554.

11. Prater $\mathrm{CD}$, Miller KE, Zylstra RG. Outpatient detoxification of the addicted or alcoholic patient. Am Fam Phys. 1999;60(4):1175-1183.

12. National Collaborating Centre for Chronic Conditions. Alcohol-use disorders. Diagnosis and clinical management of alcohol-related physical complications. NICE [homepage on the Internet]. 2010. c2013. Available from: www.nice.org.uk/ guidance/CG100/Guidance

13. Department of Health, Republic of South Africa. Regulations in terms of the Medical Schemes Act, 1998 (Act No 131 of 1998). Government Gazette. 1999. c2012. Available from: http://www.doh.gov.za/docs/regulations/1999/reg1262.pdf 